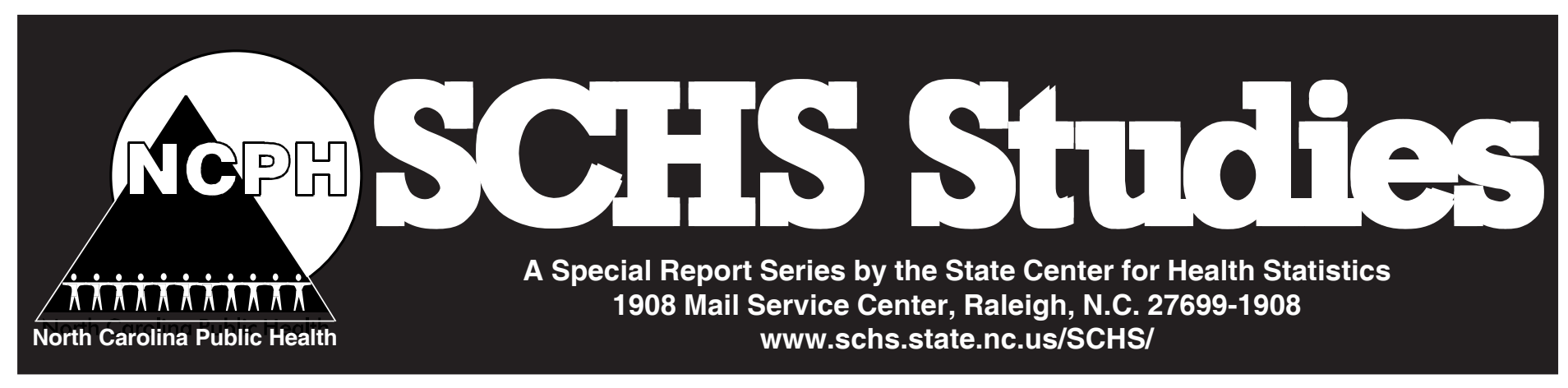

No. 149

December 2005

\title{
Predictors of Referral to the North Carolina Child Service Coordination Program Among Infants with Orofacial Clefts
}

by

\author{
Cynthia H. Cassell, MA \\ Robert E. Meyer, PhD \\ Anita M. Farel, DrPH
}

\begin{abstract}
Objectives: North Carolina has several programs that identify and refer high-risk women and children to needed services, including the Baby Love Program, which provides maternity care coordination (MCC) services, and the Child Service Coordination Program (CSCP) for children at risk for or diagnosed with special needs. This study determines the referral rates to the CSCP among infants with orofacial clefts and predictors of CSCP referral. We hypothesized that receiving Medicaid and MCC services increases the likelihood of referral to the CSCP among infants with orofacial clefts.
\end{abstract}

Methods: For 1999-2002, data were matched from the North Carolina birth certificates, the Health Services Information System, and the North Carolina Birth Defects Monitoring Program. Multivariate analysis was used to determine crude and adjusted odds ratios for selected sociodemographic variables to predict referral to the CSCP.

Results: Among a total of 644 mothers of infants with orofacial clefts, 44.7 percent were referred to the CSCP. Infants of mothers who were 30 years of age or older and mothers who had more than a high school education were significantly less likely to be referred to the CSCP. After adjusting for all covariates, the odds of infants with orofacial clefts being referred to the CSCP was 2.3 (95 percent confidence interval: $1.4,3.8$ ) for infants whose mothers received Medicaid and MCC services compared to infants whose mothers did not receive Medicaid.

Conclusions: Receiving Medicaid and MCC services were positively associated with referral to the CSCP among infants with orofacial clefts. Future studies should examine the effects of the duration of MCC services on CSCP referral and factors related to the timeliness of CSCP referral.

Note: Cynthia Cassell and Robert Meyer are with the North Carolina Birth Defects Monitoring Program, State Center for Health Statistics, Division of Public Health, North Carolina Department of Health and Human Services, Raleigh, North Carolina. Anita Farel is with the Department of Maternal and Child Health, School of Public Health, University of North Carolina at Chapel Hill, Chapel Hill, North Carolina. 


\section{Introduction}

In North Carolina, about one in every 30 infants is born with a serious birth defect. Orofacial clefts are one of the ten most prevalent serious birth defects and include cleft lip with and without cleft palate and cleft palate alone. In the U.S., for 1997-2000, the prevalence of cleft lip with and without cleft palate was 9.6 per 10,000 live births, and the prevalence of cleft palate without cleft lip was 6.3 per 10,000 live births. ${ }^{1}$

Because early intervention has been credited with promoting the health and development of infants with birth defects, identifying and referring infants with birth defects to specialized services has become an important public health goal. Birth defect surveillance systems can be instrumental in identifying and referring infants with birth defects to these services. Birth defect surveillance systems can strengthen the referral process by identifying gaps in the health care system and assisting with the development of strategies to address these gaps. These strategies include developing an automated referral system using an integrated surveillance database and employing health professionals, such as case coordinators, to facilitate referrals for specialized services. ${ }^{2-4}$

Few studies have examined factors associated with referral to specialized services among infants with birth defects. ${ }^{4-6}$ White ${ }^{5}$ examined individual and system characteristics of infants with orofacial clefts and referral to the Maryland Crippled Children's Service Program (CCSP) in the late 1960s. In that study, the infant's age at identification by the CCSP was significantly associated with cleft type, presence of other anomalies, presence of other anomalies in the family, and traveling more than 20 miles for treatment and services. Meyer ${ }^{4}$ examined referral rates to the North Carolina Child Service Coordination Program (CSCP) and identified factors associated with referral to the CSCP among live-born infants with spina bifida during 1990 to 1997. Mothers who received prenatal care in a county health department and infants from rural counties had statistically significant higher rates of referral to the CSCP. A recent study determined referral and treatment patterns of live-born Florida infants with orofacial clefts at craniofacial centers and cleft palate clinics from 1996 to 1997 . Fortytwo percent of all infants with orofacial clefts in Florida were known to the craniofacial centers or cleft palate clinics, and infants with cleft lip and palate were more likely to have had contact with the craniofacial centers or cleft palate clinics than those infants with cleft lip or cleft palate alone during this time period. ${ }^{6}$

The Baby Love Program and CSCP are two examples of North Carolina programs that identify high-risk women and children and refer them to services. In response to the high infant mortality rate in the late 1980s, the North Carolina Medicaid program expanded to improve access to health care and family support services for low-income pregnant women, postpartum women, and their children. Two key elements of this expansion, known as the Baby Love Program, included raising Medicaid eligibility to 185 percent of the federal poverty level and reimbursing for maternity care coordination (MCC) services for pregnant women who are eligible for Medicaid. A cornerstone of the Baby Love Program, MCC addresses a pregnant woman's medical, nutritional, psychosocial and resource needs, such as payment for checkups and assistance with transportation, childbirth and parenting classes, hospital care for the infant's delivery, health care for the woman and infant after the infant's birth, and referral to other programs. Such services continue through the first 60 days of the infant's life. ${ }^{\text {? }}$

Building upon the High Priority Infant Tracking Program which was initiated in 1978, the CSCP was established in 1990 to coordinate services for families of children at risk for or diagnosed with special needs to ensure access to necessary preventive, specialized, and support services for family members. Through the CSCP, a service plan 
is based on an assessment of identified strengths and needs of enrolled children and their families. Service coordination is an entitlement for eligible children under the Individuals with Disabilities Education Act and a mandate under Title V. Children eligible for the CSCP include infants and children from birth to age three who have specific parental/family, neonatal, post-neonatal, or diagnosed conditions and children age three to five with at least one of several diagnosed conditions, such as a congenital anomaly. Like MCC services, the CSCP operates statewide. However, unlike MCC services, there are no income eligibility requirements for the $\mathrm{CSCP}^{8}$ Annually, the CSCP provides community-based care coordination and service referrals for about 26,000 children. Of these children, about seven percent $(1,700)$ of children were referred to the CSCP because of a major birth defect or genetic abnormality. ${ }^{4}$

We conducted a population-based study using North Carolina birth defects registry data to compare referral rates of infants with orofacial clefts to the CSCP, a service coordination program. Our objective was to determine predictors of CSCP referral among infants with orofacial clefts. Our primary hypothesis was that receiving Medicaid and MCC services increased the likelihood of referral to the CSCP. We also hypothesized that infants whose mothers received Medicaid and MCC services would have the highest CSCP referral rate, and mothers who did not receive Medicaid would have the lowest CSCP referral rate. By pointing to areas where the referral system can be improved, this study has the potential to increase the receipt of needed specialized services by these children.

\section{Methods}

We conducted a retrospective, cohort study of liveborn North Carolina resident infants with an orofacial cleft born between January 1, 1999 and December 31, 2002. Data sources included the North Carolina birth certificates; the Health
Services Information System (MCC and CSCP data); and the North Carolina Birth Defects Monitoring Program (NCBDMP), a populationbased active surveillance program. The CSCP data were linked to the birth certificate file. A subset of infants diagnosed with an orofacial cleft was identified by the NCBDMP using the International Classification of Diseases, 9th Revision, Clinical Modification. Among a total of 712 infants with orofacial clefts in North Carolina for 1999-2002, 56 (7.9 percent) infants died during the first year of life. These infants were excluded from the analysis, along with 12 (1.7 percent) mothers who did not receive Medicaid but were indicated as receiving MCC services, yielding a sample size of 644 infants with orofacial clefts. As a result, we created an indicator variable for Medicaid and receipt of MCC services that consisted of three categories: nonMedicaid; Medicaid and receipt of MCC services; and Medicaid and no receipt of MCC services.

We determined the rate of infants with orofacial clefts referred to the CSCP for the state's six Perinatal Care Regions (PCR) (Northeastern, Northwestern, Eastern, Southeastern, Western, and Southwestern) to determine geographical differences. We also calculated CSCP referral rates for the following selected sociodemographic variables: marital status; number of living children; Special Supplemental Nutrition Program for Women, Infants, and Children (WIC) status; presence of other anomalies; infant's gender; hospital level of care at birth; source of prenatal care; and maternal age, education, and race/ ethnicity.

We conducted crude bivariate analyses, stratified analyses, and logistic regression analyses to determine predictors of CSCP referral. We employed a chi-square $\mathrm{p}$-value $<0.05$ for statistical significance in the bivariate analyses. Ninety-five percent confidence intervals were calculated for the odds ratios from logistic regression. All analyses were conducted using SAS software, version 9.1. 


\section{Results}

The majority of mothers of infants with orofacial clefts did not receive MCC services, WIC, or Medicaid (77.3 percent, 61.0 percent, and 54.8 percent respectively). However, these percentages did not differ from the percentages of all women giving birth who received MCC, WIC, or Medicaid in North Carolina. Overall, about 44.7 percent of the infants with orofacial clefts were referred to the CSCP.

Table 1 summarizes the characteristics of infants with orofacial clefts by the mother's Medicaid status and receipt of MCC services, which were the primary predictors of interest. Among the mothers who received Medicaid and MCC services, the majority (59.6 percent) of infants were referred to the CSCP. This also held true for mothers who recieved Medicaid, but who did not receive $\mathrm{MCC}$ services. Among these mothers, 53.1 percent of infants with orofacial clefts were referred to the CSCP. In contrast, among mothers who did not receive Medicaid, 35.1 percent of infants were referred to the CSCP. Among each of these three groups of women - those receiving Medicaid and $\mathrm{MCC}$, those receiving Medicaid only, and those not receiving Medicaid - the majority of infants (58.2 percent, 53.1 percent, and 55.5 percent respectively) were born at community hospitals in North Carolina.

There were statistically significant differences in CSCP referral with regard to maternal age and education, number of living children, infant's gender, hospital level of care at birth, PCR, and presence of other anomalies. For instance, infants whose mothers were 21-29 and 30 years or older were significantly less likely to be referred to the CSCP than infants whose mothers were younger than 20 years old (data not shown in tables).

Figure 1 displays the percentage of infants with orofacial clefts who were referred to the CSCP in each Perinatal Care Region. The southwestern region had the lowest percentage (35.9 percent) of infants with orofacial clefts who were referred to the CSCP; the southeastern region had the highest percentage (51.9 percent).

Several covariates were excluded from the multivariate analyses: source of prenatal care, WIC status, and PCR. Source of prenatal care and WIC status were excluded because they were highly correlated with MCC services. Perinatal Care Regions were excluded due to small cell sizes.

The crude and adjusted odds ratios (ORs) and 95 percent confidence intervals (CI) for the logistic regression results are presented in Table 2 . Adjustment for all variables revealed referral to the CSCP was significantly and independently related to Medicaid status regardless of receipt of MCC services, an infant being male (adjusted OR: 1.5), and an infant with multiple anomalies (adjusted OR: 2.5). As demonstrated by the differences in crude and adjusted ORs in Table 2, the Medicaid/ MCC indicator variable and presence of other anomalies remained as predictors of referral to the CSCP after adjustment. However, marital status, maternal race/ethnicity, and education did not remain as statistically significant predictors after adjustment. In the adjusted model in Table 2, infants whose mothers received Medicaid and MCC services had an odds of being referred to the CSCP of 2.3 compared to infants whose mothers did not receive Medicaid.

\section{Discussion}

We expected a higher CSCP referral rate among this population of infants with orofacial clefts than the 44.7 percent found here because orofacial clefts are readily apparent at birth, and these infants should be identified by the CSCP. One possible reason for the relatively low referral rate is that most infants (64.3 percent) had an isolated orofacial cleft (diagnosis of orofacial cleft only with no other birth defects). Once an orofacial cleft has been medically corrected, perhaps families may not identify a need 
Table 1: Selected characteristics of infants with orofacial clefts $(\mathrm{N}=644)$ by Medicaid status and receipt of maternity care coordination services (MCC) in North Carolina, 1999-2002

\begin{tabular}{|c|c|c|c|}
\hline & $\begin{array}{c}\text { Non-Medicaid } \\
N=353(\%)\end{array}$ & $\begin{array}{c}\text { Medicaid and } \\
\text { No Receipt of MCC } \\
\mathrm{N}=145(\%)\end{array}$ & $\begin{array}{c}\text { Medicaid and } \\
\text { Receipt of MCC } \\
N=146(\%)\end{array}$ \\
\hline \multicolumn{4}{|l|}{ Referral to CSCP } \\
\hline Yes & $124(35.1)$ & $77(53.1)$ & $87(59.6)$ \\
\hline No & $229(64.9)$ & $68(46.9)$ & $59(40.4)$ \\
\hline \multicolumn{4}{|l|}{ Receipt of WIC } \\
\hline Yes & 44 (12.5) & $87(60.0)$ & $120(82.2)$ \\
\hline No & $309(87.5)$ & $58(40.0)$ & $26(17.8)$ \\
\hline \multicolumn{4}{|l|}{ Source of Prenatal Care } \\
\hline Health Department & $16(4.5)$ & $30(2.7)$ & $78(53.4)$ \\
\hline Other & $337(95.5)$ & 115 (79.3) & $68(46.6)$ \\
\hline \multicolumn{4}{|l|}{ Maternal Age } \\
\hline$\leq 20$ years old & $23(6.52)$ & $38(26.2)$ & $52(35.6)$ \\
\hline $21-29$ years old & $160(45.3)$ & $79(54.5)$ & $81(55.5)$ \\
\hline$\geq 30$ years old & $170(48.2)$ & 28 (19.3) & $13(8.9)$ \\
\hline \multicolumn{4}{|l|}{ Maternal Race/Ethnicity } \\
\hline White/Non-Hispanic & $286(81.0)$ & $96(66.2)$ & $82(56.2)$ \\
\hline Black/Non-Hispanic & $31(8.8)$ & $22(15.2)$ & $40(27.4)$ \\
\hline Other* & $36(10.2)$ & $27(18.6)$ & $24(16.4)$ \\
\hline \multicolumn{4}{|l|}{ Maternal Education } \\
\hline$<$ High school & $33(9.4)$ & $57(39.3)$ & $73(50.0)$ \\
\hline High school & $98(27.8)$ & $56(38.6)$ & $58(39.7)$ \\
\hline > High school & $222(62.9)$ & $32(22.1)$ & $15(10.3)$ \\
\hline \multicolumn{4}{|l|}{ Marital Status } \\
\hline Married & $309(87.5)$ & $68(46.9)$ & $50(34.3)$ \\
\hline Not married & $44(12.5)$ & $77(53.1)$ & $96(65.8)$ \\
\hline \multicolumn{4}{|l|}{ Number of Living Children } \\
\hline 0 & $133(37.7)$ & $57(39.3)$ & $73(50.0)$ \\
\hline 1 & $147(41.6)$ & $45(31.0)$ & $40(27.4)$ \\
\hline$\geq 2$ & $73(20.7)$ & $43(29.7)$ & $33(22.6)$ \\
\hline \multicolumn{4}{|l|}{ Perinatal Care Region } \\
\hline Western & $22(6.2)$ & $11(7.6)$ & $24(16.4)$ \\
\hline Northwestern & $94(26.6)$ & $38(26.2)$ & $27(18.5)$ \\
\hline Southwestern & $82(23.2)$ & $21(14.5)$ & $25(17.1)$ \\
\hline Northeastern & $79(22.4)$ & $29(20.0)$ & $23(15.8)$ \\
\hline Southeastern & $39(11.1)$ & $24(16.6)$ & $16(11.0)$ \\
\hline Eastern & 37 (10.5) & $22(15.2)$ & $31(21.2)$ \\
\hline \multicolumn{4}{|l|}{ Infant's Gender } \\
\hline Male & $200(56.7)$ & $81(55.9)$ & 83 (56.9) \\
\hline Female & $153(43.3)$ & $64(44.1)$ & $63(43.2)$ \\
\hline \multicolumn{4}{|l|}{ Presence of Other Anomalies* } \\
\hline Multiple anomalies & $121(34.3)$ & $51(35.2)$ & $58(39.7)$ \\
\hline Isolated anomaly & $232(65.7)$ & $94(64.8)$ & $88(60.3)$ \\
\hline \multicolumn{4}{|l|}{ Hospital Level of Care at Birth } \\
\hline Level III teaching hospitals & $27(7.7)$ & $20(13.8)$ & $25(17.1)$ \\
\hline Level III non-teaching hospitals & $130(36.8)$ & $48(33.1)$ & $36(24.7)$ \\
\hline Community hospitals & $196(55.5)$ & $77(53.1)$ & 85 (58.2) \\
\hline
\end{tabular}

* Other = Hispanic, Native American, and Asian/Pacific Islander; Multiple anomalies = orofacial cleft + other anomaly; Isolated anomaly = orofacial cleft only 


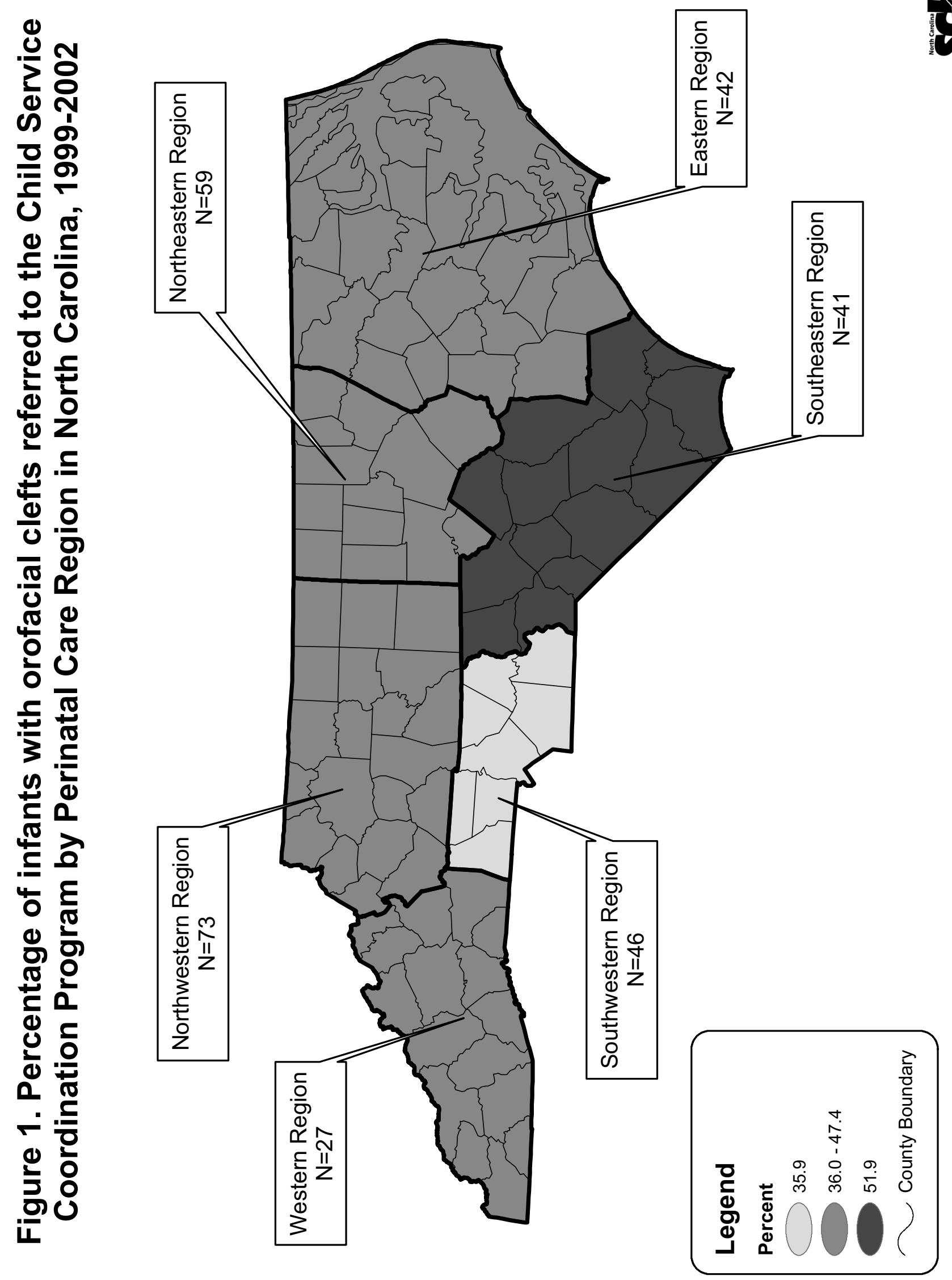


Table 2: Crude and adjusted odds ratios (OR) and 95 percent confidence intervals (CI) from logistic regression analyses for selected predictors of referral to the Child Service Coordination Program among infants with orofacial clefts in North Carolina, 1999-2002

\begin{tabular}{|c|c|c|}
\hline \multirow[b]{2}{*}{ Predictors } & \multicolumn{2}{|c|}{ Orafacial Clefts } \\
\hline & $\begin{array}{l}\text { Crude } \\
\text { OR }(95 \% \mathrm{Cl})\end{array}$ & $\begin{array}{l}\text { Adjusted }{ }^{1} \\
\text { OR }(95 \% \mathrm{Cl})\end{array}$ \\
\hline \multicolumn{3}{|l|}{ Medicaid Status and Receipt of MCC Services } \\
\hline Non-Medicaid² & 1.00 & 1.00 \\
\hline Medicaid and no receipt of MCC & $2.09(1.41,3.10)$ & $1.85(1.16,2.94)$ \\
\hline Medicaid and receipt of MCC & $2.72(1.83,4.05)$ & $2.27(1.36,3.77)$ \\
\hline \multicolumn{3}{|l|}{ Maternal Age } \\
\hline$\leq 20$ years old & $1.31(0.85,2.02)$ & $1.11(0.67,1.85)$ \\
\hline $21-29$ years old ${ }^{2}$ & 1.00 & 1.00 \\
\hline$\geq 30$ years old & $0.63(0.44,0.90)$ & $0.95(0.63,1.44)$ \\
\hline \multicolumn{3}{|l|}{ Maternal Race/Ethnicity } \\
\hline White/Non-Hispanic ${ }^{2}$ & 1.00 & 1.00 \\
\hline Black/Non-Hispanic & $1.22(0.78,1.90)$ & $0.81(0.48,1.38)$ \\
\hline Other & $1.59(1.01,2.25)$ & $1.33(0.79,2.23)$ \\
\hline \multicolumn{3}{|l|}{ Maternal Education } \\
\hline$<$ High school & $1.89(1.27,2.80)$ & $1.17(0.68,2.02)$ \\
\hline High school & $1.81(1.25,2.61)$ & $1.45(0.94,2.23)$ \\
\hline$>$ High school ${ }^{2}$ & 1.00 & 1.00 \\
\hline \multicolumn{3}{|l|}{ Marital Status } \\
\hline Not married & $1.75(1.26,2.44)$ & $1.16(0.74,1.81)$ \\
\hline Married $^{2}$ & 1.00 & 1.00 \\
\hline \multicolumn{3}{|l|}{ Number of Living Children } \\
\hline $0^{2}$ & 1.00 & 1.00 \\
\hline 1 & $0.81(0.57,1.16)$ & $0.87(0.59,1.29)$ \\
\hline$\geq 2$ & $0.80(0.53,1.19)$ & $0.77(0.47,1.23)$ \\
\hline \multicolumn{3}{|l|}{ Infant's Gender } \\
\hline Male & $1.30(0.95,1.78)$ & $1.52(1.08,2.13)$ \\
\hline Female $^{2}$ & 1.00 & 1.00 \\
\hline \multicolumn{3}{|l|}{ Presence of Other Anomalies ${ }^{3}$} \\
\hline Multiple anomalies & $2.36(1.70,3.28)$ & $2.52(1.77,3.59)$ \\
\hline Isolated anomaly ${ }^{2}$ & 1.00 & 1.00 \\
\hline \multicolumn{3}{|l|}{ Hospital Level of Care at Birth } \\
\hline Level III teaching hospitals² & 1.00 & 1.00 \\
\hline Level III non-teaching hospitals & $0.98(0.57,1.67)$ & $1.35(0.76,2.41)$ \\
\hline Community hospitals & $0.84(0.51,1.40)$ & $1.15(0.66,2.01)$ \\
\hline
\end{tabular}

${ }^{1}$ Odds ratios adjusted for all covariates in full model, including marital status, hospital level of care at birth, number of living children, infant's gender, presence of other anomalies, maternal age, education, and race/ethnicity, and Medicaid and MCC services indicator variable

${ }^{2}$ Referent

${ }^{3}$ Multiple anomalies = orofacial cleft + other anomaly; Isolated anomaly = orofacial cleft only 
for other non-medical services. In contrast, an infant with multiple anomalies usually requires additional medical and non-medical services.

The lower than anticipated referral rates also could be attributed to infants being referred to craniofacial centers in the state. The University of North Carolina Craniofacial Center in Chapel Hill and the North Carolina Center for Cleft and Craniofacial Deformities in Winston-Salem are two such centers. These centers provide a coordinated, interdisciplinary team approach to care for families of infants with craniofacial anomalies. The interdisciplinary teams include physicians and health care professionals from different specialties, such as audiology, genetics, neurosurgery, oral and maxillofacial surgery, orthodontics, and social work. ${ }^{9}$ This arrangement may be perceived by families as reducing the need for service coordination.

Some of our findings are not congruent with previous studies of CSCP conducted in North Carolina. ${ }^{4,10}$ The study by Meyer found 79.8 percent of infants with spina bifida who were born during 1990 to 1993 were referred to the CSCP. ${ }^{4}$ Farel and Herrick found 79.1 percent of very low birth weight infants were referred to the CSCP in 1991 and 74.1 percent of very low birth weight infants were referred to the CSCP in 1993. ${ }^{10}$ These studies showed substantially higher CSCP referral rates than our study. However, these studies and our study showed similar geographical differences in the CSCP referral rates. ${ }^{4,10}$

The differences in referral rates among the various PCR warrant additional research on the identification and referral procedures employed at the county and hospital level and at local health departments. ${ }^{4,10}$ A variety of health care professionals refer families and infants to the CSCP, including physicians, staff nurses, community transition coordinators, risk managers, and hospital discharge staff. Despite a standard protocol for referring infants, our findings suggest that efforts to strengthen the referral rate in certain PCR of the state could substantially increase the overall referral rate to the CSCP among infants with orofacial clefts. Previous studies have yielded similar results. ${ }^{4,10}$

Other possible explanations exist for the differences in CSCP referral rates across the various PCR. For example, families living in the eastern part of the state may go to Virginia for services and thus may not be referred to the CSCP in North Carolina. Similarly, individuals in the western region of the state have been reported to not participate as readily in government-sponsored programs.

The findings from this study also suggest that certain hospitals may better understand the benefits of CSCP. Additional qualitative research at the local level may identify barriers to referral to specialized services like the CSCP among families of infants with birth defects.

A strength of this study includes examining predictors of CSCP referral while controlling for certain sociodemographic characteristics, such as number of living children; presence of other anomalies; hospital level of care at birth; and maternal age, education, and race/ethnicity.

The results from this study should be interpreted with caution because of small sample sizes, which were sometimes unevenly distributed. A potential source of bias is that some families might have refused referral to the CSCP. In addition, cleft type was not examined due to small sample sizes, which may have influenced the results.

Despite these limitations, findings from this study have important implications for program outreach and evaluation, policy development, and increasing access to services, especially for infants with birth defects such as orofacial clefts. This study suggests that the MCC program is meeting its goal of increasing referrals to needed services. This study and others suggest that population-based birth defects surveillance systems can play an integral role in child-find efforts to identify infants with 
birth defects and refer them to specialized health services. Future studies should examine the effect of duration of MCC services on CSCP referral and factors related to the timeliness of CSCP referral.

\section{References}

1. National Birth Defects Prevention Network. Birth defects surveillance data from selected states, 1997-2001. Birth Defects Research (Part A) Clinical and Molecular Teratology 2004;70:741-43.

2. Correa A, Edmonds L. Birth defects surveillance systems and oral clefts. In: Wyszynski DF, editor. Cleft lip and palate. New York: Oxford University Press; 2002:117-26.

3. Farel AM, Meyer RE, Hicken M, Edmonds LD. Registry to referral: using birth defects registries to refer infants and toddlers for early intervention services. Birth Defects Research (Part A) Clinical and Molecular Teratology 2003;67:647-50.

4. Meyer RE. Child Service Coordination Program coverage for infants with spina bifida. Raleigh, North Carolina, State Center for Health Statistics Statistical Brief 1998;16:1-4.

5. White RB. Services for children with congenital facial clefts through a state crippled children's service program. Cleft Palate Journal 1981;18:116-21.
6. Williams CA, Mardon RE, Grove D, Wharton P, Hauser KW, Frias JL. Treatment of oralfacial clefts by state affiliated craniofacial centers and cleft palate clinics. Birth Defects Research (Part A) Clinical and Molecular Teratology 2003;67:643-46.

7. North Carolina Department of Health and Human Services, Division of Public Health, Women's and Children's Health Section. Programs and Services of the Women's and Children's Health Section. Raleigh: Department of Health and Human Services; 2003.

8. North Carolina Department of Health and Human Services, Division of Public Health, Women's and Children's Health Section, and North Carolina Division of Medical Assistance. North Carolina Child Service Coordination Program Manual. Raleigh: Department of Health and Human Services; 1999.

9. Strauss RP. The organization and delivery of craniofacial health services: the state of the art. Cleft Palate Craniofac J 1999;36:189-95.

10. Farel AM, Herrick H. Statewide coverage of very low birth-weight infants and young teenage mothers in North Carolina's Child Service Coordination Program. J Public Health Management Practice 1997;3:58-63. 


\section{Acknowledgements}

This project was partially funded by a cooperative agreement for the development and improvement of population-based birth defects surveillance programs and the integration of surveillance data with public health programs in conjunction with the National Center on Birth Defects and Developmental Disabilities, Centers for Disease Control and Prevention, Atlanta, Georgia; the Department of Maternal and Child Health, School of Public Health, University of North Carolina at Chapel Hill, Chapel Hill, North Carolina; and the North Carolina Birth Defects Monitoring Program, State Center for Health Statistics, Division of Public Health, North Carolina Department of Health and Human Services, Raleigh, North Carolina (Grant Number: U50/CCU416075-02).

The authors thank the staff of the North Carolina Birth Defects Monitoring Program and the State Center for Health Statistics, especially Fatma Simsek, Dorothee Schmid, Michelle Lown, and Dianne Enright, for their assistance in this project. In addition, we thank Christina Venturi with the North Carolina Birth Defects Monitoring Program; Paul Buescher with the State Center for Health Statistics; Julie Daniels with the Department of Maternal and Child Health, School of Public Health, University of North Carolina at Chapel Hill; and Carol Tant, Cheryl Lowe, Cathy Kluttz, and Vienna Barger from the North Carolina Women's and Children's Health Branch, Division of Public Health, for their valuable comments on previous drafts. 
State of North Carolina

Michael F. Easley, Governor

Department of Health and Human Services

Carmen Hooker Odom, Secretary

Division of Public Health

Leah Devlin, D.D.S., M.P.H., State Health Director

State Center for Health Statistics

Paul A. Buescher, Ph.D., Director

www.schs.state.nc.us/SCHS/
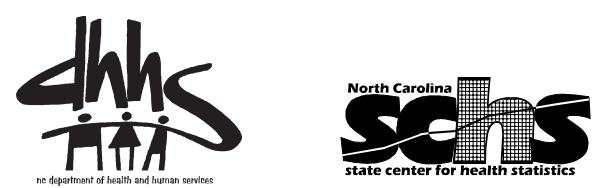

The NC Department of Health and Human Services does not discriminate on the basis of race, color, national origin, sex, religion, age or disability in employment or the provision of services.

Department of Health and Human Services

State Center for Health Statistics

1908 Mail Service Center

Raleigh, NC 27699-1908

919-733-4728 